\title{
AVALIAÇÃO DA APRENDIZAGEM DO ALUNO COM DEFICIÊNCIA NA PERSPECTIVA DA INCLUSÃO ESCOLAR
}

\author{
EVALUACION DEL APRENDIZAJE DEL ALUMNO COM DISCAPACIDAD EN \\ LA PERSPECTIVA DE LA INCLUSIÓN ESCOLAR
}

\section{EVALUATION OF STUDENT DISABILITY LEARNING IN THE PERSPECTIVE OF SCHOOL INCLUSION}

\author{
Romária de Menezes do NASCIMENTO ${ }^{1}$ \\ Ana Cristina Silva SOARES ${ }^{2}$ \\ Rejane Maria Gomes da SILVA ${ }^{3}$ \\ Francisco Ricardo Miranda PINTO ${ }^{4}$
}

RESUMO: Este tem como temática central a avaliação da aprendizagem na Educação Especial. O objetivo geral é verificar como se dá a avaliação da aprendizagem do aluno com deficiência na escola, com base na prática avaliativa do professor da sala regular e do professor do Atendimento Educacional Especializado (AEE). Para melhor entender e compreender a temática, buscou-se apoio teórico em Hoffmann (2007), Luckesi (1997) e Perrenoud (1999) voltados à avaliação da aprendizagem e a Mittler (2003), Fernandes e Viana (2009) voltados à avaliação numa perspectiva inclusiva, entre outros. Trata-se de pesquisa qualitativa com abordagem descritiva, realizada na escola META, nome fictício, localizada no município de Sobral, no Estado do Ceará, utilizando como instrumento de coleta de dados a entrevista aplicada à duas professoras. Os dados foram analisados à luz da literatura apontada no texto. As considerações finais indicam que, de maneira geral, a avaliação do aluno com deficiência se reveste de tanto ou maior complexidade que as demais, que os critérios e instrumentos utilizados dependem ou respeitam uma série de fatores, porém se tratando da experiência descrita percebe-se o compromisso da escola na construção de conhecimentos por esse aluno e a devida avaliação deste conhecimento.

PALAVRAS-CHAVE: Avaliação. Aprendizagem. Inclusão.

RESUMEN: Esto tiene como temática central la evaluación del aprendizaje en la Educación Especial. El objetivo general es verificar cómo ocure la evaluación del aprendizaje del alumno con discapacidad en la escuela, con base en la práctica evaluativa del profesor de la sala regular y del profesor del Atendimiento Educativo

${ }^{1}$ Pedagoga. Professora da Rede Municipal de Educação de Sobral - CE - Brasil. E-mail: romaria.menezes@hotmail.com.

${ }^{2}$ Universidade Estadual Vale do Acaraú (UVA), Sobral - CE - Brasil. Docente do Curso de Pedagogia. Doutora em Educação. E-mail. acsilvasoares@gmail.com.

${ }^{3}$ Universidade Estadual Vale do Acaraú (UVA), Sobral - CE - Brasil. Docente do Curso de Pedagogia. Doutora em Ciências da Educação. E-mail: rejanemgs@gmail.com.

${ }^{4}$ Universidade Estadual Vale do Acaraú (UVA), Sobral - CE - Brasil. Docente do Curso de Pedagogia. Docente do Curso de Pedagogia EaD do Centro Univesitário INTA (UNINTA). Professor da Rede Municipal de Educação de Varjota-CE. E-mail: ricardomiranda195@gmail.com. 
Especializado (AEE). Para mejor comprensión la temática se buscó apoyo teórico en Hoffmann (2007), Luckesi (1997), Perrenoud (1999), orientados a la evaluación del aprendizaje y Mittler (2003), Fernandes y Viana (2009), orientados a la evaluación desde una perspectiva Incluyendo, entre otros. Se trata de una investigación cualitativa con enfoque descriptivo, realizada en la escuela META, nombre ficticio, ubicada en el municipio de Sobral en el Estado de Ceará utilizando como instrumento de recolección de datos la entrevista aplicada a dos profesoras. Los datos fueron analizados a la luz de la literatura señalada en el texto. Las consideraciones finales indican que, de manera general, la evaluación del alumno con discapacidad se reviste de tanto o mayor complejidad que las demás, que los criterios e instrumentos utilizados dependen o respetan una serie de factores, pero si se trata de la experiencia descrita se percibe El compromiso de la escuela en la construcción de conocimientos por ese alumno y la debida evaluación de este conocimiento.

PALABRAS CLAVE: Evaluación. Aprendizaje. Inclusión

ABSTRACT: This study focuses on the assessment of Special Education learning. Its general goal is to analyze how the learning assessment of disabled students happens at school, based on the evaluation practices of a regular classroom teacher and a teacher from the Specialized Educational Service (SES). In order to better understand this theme, this study was supported by the theories of Hoffmann (2007), Luckesi (1997) and Perrenoud (1999) from learning assessment field, Mittler (2003), Fernandes and Viana (2009) focused on evaluation in an inclusive perspective, among others. It is a qualitative research with a descriptive approach that was carried out at META school (fictitious name), which is located in the municipality of Sobral in the State of Ceará. An interview with two teachers was used as instrument of data collection and these data were analyzed based on the literature pointed out in the text. The concluding remarks, by and large, indicate that the assessment of a disabled student is just as, if not more, complex than the other ones. The criteria and instruments used respect or depend on a number of factors, but when it comes to the described experience, it is possible to see the school commitment concerning this student construction of knowledge and the proper assessment to this process.

KEYWORDS: Assessment. Learning. Inclusion.

\section{Introdução}

A abordagem da temática "avaliação da aprendizagem do aluno com deficiência e inclusão escolar" traz à tona a importância tanto da avaliação educacional quanto da inclusão escolar. A escassez de estudos e a pouca problematização da temática reforçaram ainda mais a relevância do desenvolvimento desta pesquisa. Inicialmente depreende-se uma responsabilidade maior pela aprendizagem deste aluno em torno da professora do Atendimento Educacional Especializado (AEE), o que é inadequado, já que isto deve ser uma responsabilidade dos professores, em geral. 
Estabeleceu-se como objetivo geral verificar como se dá a avaliação da aprendizagem dos alunos com deficiência na escola, com base na prática avaliativa do professor da sala regular e do professor do AEE.

A pesquisa de abordagem qualitativa do tipo descritiva se deu na escola META (nome fictício), localizada no município de Sobral - Ceará, com duas professoras, utilizando como instrumento de coleta de dados a entrevista realizada a partir de perguntas abertas previamente preparadas e tomando por orientação os objetivos pretendidos na pesquisa, analisadas à luz da literatura contemplada como referencial teórico.

Para melhor posicionamento e inferências acerca da temática "avaliação" utilizou-se das teorizações de Luckesi (1997), Hoffmann (2007), Perrenoud (1999) Mittler (2003), Fernandes e Viana (2010). Para conhecer e descrever algumas práticas avaliativas do professor da sala multifuncional, que concerne ao Atendimento Educacional Especializado (AEE) permanece as ideias dos autores Mittler (2003), Fernandes e Viana (2010).

De maneira geral, observou-se da fala das professoras que a escola adota um modelo de avaliação formativo voltado para os alunos com deficiência. Porém são perceptíveis lacunas do ponto de vista conceitual acerca do que é avaliação da aprendizagem e sobre os instrumentos avaliativos há uma preocupação das professoras em utilizá-los, levando em consideração a deficiência e as possibilidades do aluno. No tocante à avaliação da aprendizagem e inclusão escolar, nenhuma professora estabelece com devida clareza a relação entre as mesmas.

\section{Da inclusão nos documentos oficiais à avaliação da aprendizagem}

Já remonta do Séc. XIX as primeiras ações voltadas à minoria de estudantes que necessitavam de Educação Especial e Inclusiva no Brasil, informalmente trazidas da Europa. Na década de 60 do Séc. XX na Lei de Diretrizes e Bases da Educação Nacional, Lei $\mathrm{N}^{\mathrm{o}}$ 4.024/61 (LDBEN) os direitos dos ditos 'alunos excepcionais' ganham corpus a partir do Art. 88, que indica a integração dos excepcionais no que for possível e assim à comunidade (BRASIL, 1961).

A Constituição Brasileira (CF) de 1988 faz a primeira menção, ainda que velada, da Educação Inclusiva em seu Art. 205 ao relatar "A educação, como um direito de todos, garantindo o pleno desenvolvimento da pessoa, o exercício da cidadania e a 
qualificação para o trabalho" (BRASIL, 1988, p. 117). Em consecução está o Estatuto da Criança e do Adolescente que traz, explicitamente, em seu Art. 54 “[...]: III atendimento educacional especializado aos portadores ${ }^{2}$ de deficiência, preferencialmente na rede regular de ensino.” (BRASIL, 2014, p. 33).

A Lei de Diretrizes e Bases da Educação Nacional (LDBEN) N $^{\circ}$ 9.394/96, reserva, em sua nova redação, o Capítulo V inteiro à Educação Especial - nomenclatura mais ampla - e em seu Art. 59 alterado pela Lei № 12.796/2013 preconiza que "Os sistemas de ensino assegurarão aos educandos com deficiência, transtornos globais do desenvolvimento e altas habilidades ou superdotação.”. (BRASIL, 2013, p. 3).

Estes documentos oficiais instituíam a construção dos princípios e diretrizes voltados à Educação Inclusiva que acontece, bem posteriormente, com a publicação das Diretrizes Nacionais Para a Educação Especial na Educação Básica em 2001, e ainda mais tarde, a Política Nacional de Educação Especial na perspectiva da Educação Inclusiva em 2008, documento voltado para reforçar a inclusão destes alunos nas salas regulares.

A presença do aluno com deficiência na escola demanda a execução de ajustes físicos, humanos, curriculares, pedagógicos e, sobretudo, avaliativos para que, de fato, a educação inclusiva se consolide com a efetiva participação do aluno a partir do conhecimento construído pelo mesmo.

Outro mecanismo legal, o decreto $\mathrm{n}^{\mathrm{o}} 7.611$, de 17 de novembro de 2011, dispõe sobre o Atendimento Educacional Especializado, fomentando o desenvolvimento de recursos didáticos e pedagógicos que eliminem as barreiras no processo de ensino e aprendizagem, sendo necessárias adaptações nas avaliações, sob a orientação do Professor do AEE.

A aprendizagem do aluno deve ir além apenas de conteúdos curriculares e sob a ótica da educação inclusiva, não se concebe, portanto, que o aluno com deficiência esteja integrado na escola, mas não tenha uma dinâmica de avaliação que acompanhe o que é construído por ele a partir de suas perspectivas. Antes, a avaliação do aluno com deficiência deve ser "[...] processo dinâmico [...], prevalecendo na avaliação os aspectos qualitativos que indicam as intervenções pedagógicas do professor.” (BRASIL, 2008, p. $11)$.

A avaliação da aprendizagem do aluno com deficiência, bem como do aluno sem deficiência demanda uma intencionalidade no processo, proposto principalmente

${ }^{2}$ Termo extinto segundo a Portaria SEDH No de 2.344, de 3 de novembro de 2010. 
quando há um engajamento real. Assim a avaliação da aprendizagem é um fim seguinte ao planejamento tendo em vista que somente é possível a partir do que foi devidamente planejado e executado. (LUCKESI, 2010)

Quando, porém, a avaliação não se faz possível, é comum inferir que não houve uma intencionalidade pedagógica, sendo, portanto, impossível aferir a construção de conhecimentos do aluno. Tal concepção destaca a avaliação como um fator excludente na escola. A avaliação tem por base acolher uma situação para então, e só então, ajuizar sua qualidade, tendo em vista dar-lhe suporte de mudança, se necessário (LUCKESI, 1997). Nesta perspectiva Hoffmann (2009, p. 34) ratifica que a

Inclusão pode representar exclusão sempre que a avaliação for para classificar e não para promover, sempre que as decisões levarem em conta parâmetros comparativos, e não as condições próprias de cada aluno e o princípio de favorecer-lhe oportunidade máxima de aprendizagem, de inserção na sociedade, em igualdade de condições educativas. Essa igualdade nada tem a ver com a visão padronizada da avaliação, como uma exigência de igualar-se aos colegas, de corresponder às exigências de um currículo fixo, ou de um professor. Tem a ver com a exigência de delinear-se concepções de aprendizagem e formar-se profissionais habilitados que promovam condições de escolaridade e educação a todas as crianças e jovens brasileiros em sua diversidade.

A atenção para o instrumento coerente com a

habilidade/peculiaridade/possibilidade do aluno torna possível a avaliação e melhor a inclusão do aluno. São eles, os instrumentos, que manifestam a intimidade do educando, inclusive seu modo de aprender. Para a construção dos mesmos é necessário compatibilizá-los com as habilidades. Caso haja contrariedade quanto a estes aspectos a avalição não se dá e o processo de aprendizagem fica em demasiado, comprometido (LUCKESI, 1997).

Nesta mesma linha Perrenoud (1999) expressa algumas atitudes que favorecem e viabilizam a realização de uma avaliação com o viés inclusivo: reexplicação, desaceleração do ritmo, voltar para trás ou adotar um modo mais concreto de exposição. Isso implica na diferenciação do ensino que pretende atender a necessidade de cada um. No caso do aluno com deficiência, suas necessidades, por muitas vezes, são atendidas na realização do que acabou de ser citado.

Sobre o que, porventura, inviabiliza a prática de uma avaliação formativa Perrenoud (1999) alerta acerca de sua impossibilidade manifestada na falta de espaços lúdicos, a quantidade de alunos, o engessamento das práticas pedagógicas e do sistema 
educacional. Por outro lado, o mesmo autor refere que a apropriação é uma reconstrução das intenções que segundo ele é própria da prática de avaliação formativa destacando não ser, aquela, ponto de interesse do professor que ainda mantém o discurso do fracasso como continuidade na perspectiva de rotular o bom e o ruim aluno, de visualizar-se apenas professor, responsável pelas aulas e não de manusear a aprendizagem.

Aqui convém destacar que a aprendizagem do aluno com deficiência, assim como as demais, é uma responsabilidade do professor, bem como de toda a escola a partir de sua organização pedagógica. A diversidade de metodologias, a atenção e a regulação individualizada a partir da necessidade do aluno, se fazem necessárias para verdadeiramente caracterizar a existência de uma escola que pratica uma avaliação com abordagem formativa.

\section{Concepções de avaliação da aprendizagem}

A maioria das divisões quanto aos períodos e tipos de avaliações existentes coincide em apontar Tyler como o grande nome a marcar a área a ponto de ser chamado 'pai da avaliação educativa' em 1930, nos Estados Unidos, quando propôs um modelo sistemático de avaliação que consistia em comparar objetivos pretendidos com os alcançados, sendo, portanto, um modelo de análise quantitativa, segundo seu pensamento, um modelo de avaliação somativa, executada no final do processo (VIANNA, 2000).

Na década de 60 surgiu o modelo de avaliação formativa proposto por Scriven que relacionou como objetivo da avaliação educacional determinar o valor do mérito do que está sendo avaliado e diferenciou as avaliações de natureza somativa e formativa, sendo a primeira executada ao final do processo de aprendizagem e a segunda, durante esse processo (FURLANETTO, 2006; VIANNA, 2000; PARREIRA; SILVA, 2015).

O método chamado de 'pedagogia do exame', já registrado na China, na Idade Média, trata-se de outro tipo de avaliação, centrado na resolução de provas, onde as notas se tornam principal indicativo de sucesso ou fracasso e consequentemente forma punitiva, leva em consideração somente o que é feito na "prova", desconsidera, pois o caminho que o aluno percorreu (LUCKESI, 2010; PONTES JUNIOR et al, 2016).

O medo é, então, característica da pedagogia do exame e esta se assemelha à pedagogia Comeniana (Protestante), onde o medo é um excelente fator para manter a 
atenção dos alunos. Não diferente, a pedagogia Jesuítica (séc. XVI) tinha por objetivo a construção de uma hegemonia católica contra as possibilidades heréticas, especialmente as Protestantes. Davam muita importância às provas e exames, bem como à divulgação de seus resultados (LUCKESI, 2010; BARBOSA; MIRANDA, 2017).

$\mathrm{O}$ ato de avaliar deve obedecer à uma sequência que leve o aluno a aprendizagem consolidada. Os fatores que fazem parte dessa sequência dizem respeito ao conhecimento do aluno a partir de suas necessidades e carências a fim de promover intervenções no processo de ensino-aprendizagem por meio de avaliações que procurem abranger a maioria, se não todas as características dos alunos.

Inicialmente, deve-se ter a iniciativa de acolher todos os problemas ou deficiências do aluno. A partir da análise feita, deve-se proceder ao diagnóstico, um conhecimento adquirido através de dados que qualificamos e, por isso, nos permite uma decisão e uma intervenção. A situação diagnosticada, seja ela positiva ou negativa a partir da avaliação, para se completar, necessita da tomada de decisão.

O que significa dizer que a decisão do que fazer com a realidade avaliada se impõe no ato de avaliar, pois que, em si mesmo, ele contém essa possibilidade. Mais do que isso: a tomada de decisão é uma necessidade para que o ato de avaliar se conclua e se concretize. Dessa forma, o modelo de avaliação proposto deve ser inclusivo, amoroso, dinâmico e construtivo (LUCKESI, 1997, 2010).

Dentro dessas propostas encontra-se também o modelo de avaliação formativo mediador elaborado por Hoffmann. Este modelo consiste em sempre tomar posturas reflexivas diante das práticas avaliativas, a fim de melhorar os resultados com relação à aprendizagem dos educandos. Neste, o professor é o mediador entre o aluno e o conhecimento. Fundamenta-se na interlocução, interpretação e diálogo. Nela, o erro do educando se torna uma ferramenta de aprendizagem (HOFFMANN, 2009).

A avaliação visando à promoção da aprendizagem destina grande importância ao papel mediador do professor, que lança um olhar mais apurado sobre o aluno, aproximando-se dele, procurando interpretar suas manifestações para compreender seu desenvolvimento. $\mathrm{O}$ erro adquire uma imagem positiva, pois através dele o professor pode acompanhar e intervir diretamente no processo de aprendizagem e ajudar o aluno a aprender e a se desenvolver (HOFFMANN, 2005; PERRENOUD, 1999).

A avaliação formativa considera a reação de quem recebe a partir do pressuposto de ajuste ou regulação das aprendizagens, refletido nas práticas de reexplicação, desaceleração do ritmo, voltar para trás ou adotar um modo mais concreto de exposição. 
(PERRENOUD, 1999). A avaliação dialógica, por sua vez, constrói-se a partir do diálogo estabelecido entre educador e educandos. O professor deixa de ser o detentor único do conhecimento, passa a construir conhecimentos na relação com o educando e vice-versa. Através dela também se torna possível averiguar e avaliar o que de aprendizado o aluno vem construindo (FREIRE, 1981).

Em outra perspectiva, destacamos a relação entre avaliação e alunos com deficiências; os estudos de Susan Stainback (2005) apontam ser prejudiciais as avaliações padronizadas na prática educacional de ensinar apenas para ser bem sucedido na prova, a fim de salvar os alunos, os professores e as escolas da humilhação de obterem rotulados como fracassados. Ensinar fatos ou números decorados não faz nada em prol do desenvolvimento de um indivíduo crítico ou possuidor de um desejo duradouro pelo aprendizado. Além do que, essa atitude não reconhece ou estimula o aproveitamento dos pontos fortes dos alunos.

Ainda segundo a mesma autora, as avaliações que realmente levam em conta a singularidade dos alunos, as habilidades e conhecimentos necessários ao funcionamento do aluno na sociedade podem ajudá-los a identificar e entender o que eles precisam para serem bem-sucedidos sem desmoralizar suas noções de indivíduo.

\section{Metodologia}

A pesquisa é de abordagem qualitativa do tipo descritiva. Na pesquisa qualitativa, "o pesquisador buscará compreender o significado que os outros dão às suas próprias práticas.” (SANTOS FILHO, 1997, p.43).

O universo do estudo foi a Rede Municipal de Educação do Município de Sobral, cidade situada à porção noroeste do Estado do Ceará, com população aproximada de $200 \mathrm{mil} / \mathrm{hab}$. De clima semiárido, é a quarta maior economia do estado cearense, sendo destaque na educação, no cenário nacional por suas escolas que se destacam nas avaliações externas, sobrepondo, inclusive as médias nacionais.

O lócus da pesquisa foi a escola META (nome fictício), tendo como participantes duas professoras sendo uma da sala regular (Professora do $1^{\circ}$ ano) e a outra do Atendimento Educacional Especializado da referida escola. O critério de inclusão utilizado é que as professoras fossem estatutárias da Rede Municipal de Educação e como exclusão adotou-se o critério de licença médica e ou transferência no transcorrer da pesquisa. 
Para a coleta de dados foi utilizado como instrumento a entrevista composta por um roteiro de perguntas previamente estabelecido com sete perguntas à professora da sala regular e seis à professora do AEE sendo cinco perguntas comuns às duas professoras, uma diferenciada às duas e uma a mais feita à professora da sala regular. A escolha pela entrevista se justifica pela interação estabelecida, o que favorece uma interrelação entre pesquisador e pesquisado.

A entrevista foi realizada em um ambiente à parte da escola na busca do mínimo de interferências possíveis, todavia ainda existiram ligeiras interferências que não comprometeram a qualidade do instrumento de coleta de dados. Buscaram-se dados importantes acerca da concepção de avaliação da aprendizagem, dos processos avaliativos voltados ao aluno com deficiência e da relação estabelecida entre avaliação da aprendizagem e efetiva inclusão escolar que os professores concederam.

O tratamento e a análise dos dados foram realizados à luz da literatura apontada ao longo do referencial teórico utilizado no estudo. Para fins didáticos denominou-se P1 a Professora da Sala Regular e P2 a Professora da Sala do AEE.

\section{Análise e discussão dos dados}

Opta-se inicialmente em descrever o perfil sociodemográfico básico dos sujeitos participantes da pesquisa. Sobre a formação das entrevistadas a professora da sala regular tem 24 anos, leciona há três anos, sendo recém-formada. A professora do AEE tem 61 anos, com experiência tanto no ensino como na gestão escolar, com vinte e nove anos de profissão. Cada análise segue a pergunta direcionada aos objetivos da pesquisa, havendo, portanto, três eixos de análise.

\section{Concepção de avaliação da aprendizagem pelo professor do aluno com deficiência}

Sobre a concepção de avaliação da aprendizagem do aluno com deficiência a participante P1 revela uma concepção de avaliação formativa, realizada durante o processo de aprendizagem. Por sua vez P2 apresenta uma visão mais restrita de avaliação da aprendizagem o que permite inferir a relação com sua prática no sentido de ser mais individualizada e voltada para o aluno, sua deficiência, sua necessidade e potencialidade. 
Eu acredito que a avaliação da aprendizagem seja a gente vê o aluno como um todo, não só a parte cognitiva, mas também a parte social e aí a gente tentar ver não só a meta que o aluno tem que atingir, mas também ver o que ele já evoluiu. (P1)

Para mim avaliação é eu saber do resultado do trabalho que eu fiz com cada criança. Eu trabalho com diversos níveis de crianças especiais então assim minha avaliação é do trabalho que eu faço, do resultado que eu conseguir descobrindo a capacidade de cada um. (P2)

Autores como Luckesi (1997) e Hoffmann (2009) defendem e representam esta abordagem e dão conta de que é necessário acolher o aluno em toda sua amplitude com suas múltiplas possibilidades e também carências para só então ser possível uma intervenção e coerente avaliação da aprendizagem do educando.

Ainda sobre isso, Luckesi confirma a concepção da professora ao assinalar que o desenvolvimento do educando deve indicar também o desenvolvimento de diversas áreas do ser humano: cognitivo, pedagógico, entre outros. É função do professor uma sensibilidade à observância de todos estes fatores no educando. É possível perceber também na fala da professora que o aspecto cognitivo parece se dividir igualmente com o aspecto social, o que pressupõe que a professora considera de grande valia na sua avaliação os aspectos sociais como parâmetro avaliativo (LUCKESI, 1997).

O exposto por P2 vai de encontro ao que Anache e Resende (2016), Monteiro, Camargo e Freitas (2016) apontam, em seus estudos realizados em Mato Grosso do Sul e em São Paulo, respectivamente, como sendo o caminho oposto da avaliação com crianças deficientes. Aqueles estudos indicam que a melhor avaliação é aquela que considera os conhecimentos já adquiridos e como são sistematizados pelos alunos com deficiência e não vendo a criança como um laudo médico.

Aqui, mais estritamente, se dá de forma mais efetiva em relação à sala regular o processo de acolhimento de uma situação, para daí ajuizar sua qualidade e suas possíveis adequações. Assim, também a intencionalidade do processo de ensino aprendizagem e consequente prática avaliativa - são mais direcionadas. Por fim, porém destacar que a professora sobrepõe o significado de avaliação da aprendizagem à sua prática, denotando certo estranhamento quanto à amplitude do conceito.

\section{Conhecer os processos avaliativos voltados para o aluno com deficiência}


Os critérios e instrumentos que são utilizados nesta avaliação se apresentam como importante aspectos a serem observados no processo avaliativo, de forma muito peculiar, com as crianças com deficiências, superdotação, altas habilidades ou quaisquer transtornos de aprendizagem, é preciso ter métodos e metodologias precisas não na perspectiva de ser diferente para diferentes, mas adequadas para as necessidades de cada um conforme.

\begin{abstract}
Na sala regular nós utilizamos o mesmo material que utilizamos com os outros alunos que é a provinha que a gente faz questões, só que quando a gente vai aplicar ao aluno que tem alguma deficiência a gente faz a parte, separado. Somente a professora e o aluno no momento em que a professora esteja disponível e aí a professora vai lendo e vendo qual o conhecimento que o aluno realmente tem, porque, por exemplo, nas questões de Ciências, Historia, tem muita coisa relacionada ao cotidiano da criança e que ela sabe responder o nome do pai, quantas pessoas tem na família e ai a gente leva em consideração não ela saber interpretar a pergunta lendo, mas se ela sabe responder àquela pergunta que tem na prova. (P1).

Depende muito da deficiência, já trabalhei com crianças com Paralisia Cerebral que eles não falavam, não tinham nenhum movimento e eu conseguia avaliar através das expressões faciais (ri, ficar sério) e as outras crianças avalio mesmo avaliando a escola que eles reconhecem daquilo que eu tenho trabalhado com eles. (P2)
\end{abstract}

As falas clarificam que a avaliação é homogênea, ainda que se verifique a busca pela adaptação à realidade pedagógica do aluno, havendo, portanto, uma diferenciação na aplicação do instrumental avaliativo não avaliando, por exemplo, a capacidade de leitura ou interpretação do aluno, mas sua resposta oral baseado no conhecimento que tem.

A diferenciação na aplicação deste instrumento confere grande ajuda para a aprendizagem bem como para o professor melhor mensurar o aprendizado que o aluno realizou e atende à avaliação com perspectivas de reflexão da práxis pedagógica do próprio professor, assim como no desenvolvimento do aluno (BRASIL, 2001).

Quanto à resposta da P2 fica evidente devida pertinência, tendo em vista, sua prática que o critério e instrumento utilizado tem estreita relação com a deficiência do aluno, sem destoar do preconizado pelas Estratégias 3 Orientações Para a Educação de Crianças Com Necessidades Educacionais Especiais que assegura a alternância na prática pedagógica a partir de cada necessidade dos estudantes (BRASIL, 2001).

Este papel deve ser comum tanto ao professor da sala regular quanto ao professor do AEE, pois os mesmos devem observar os alunos, principalmente a partir de 
suas dificuldades, visualizar novas metodologias que contemplem as dificuldades expressas pelos alunos. Isto exige, do educador uma atitude de sensibilização e mobilização que reflita, posteriormente na prática pedagógica.

Segundo Fernandes e Viana (2010) a avaliação apresenta características complexas, diante de suas especificidades. A inexistência de uma avaliação adequada colabora para validar preconceitos com relação às pessoas com deficiência. A complexidade da avaliação também é citada por Hoffmann (2008), pois é instrumento para compreender avanços individuais e coletivos dos alunos.

\title{
Relevância da avaliação da aprendizagem para a efetiva inclusão escolar
}

Ao ser consultada sobre o que justifica ou influencia o seu processo avaliativo para que ele seja da forma que foi citado anteriormente P1 destaca:

\begin{abstract}
Bom como aqui a gente tem dois métodos de avaliação que são na sala regular com a provinha normal e tem o AEE. No AEE a professora de lá faz uma avaliação mais voltada para o que ela está precisando que é saber se ela já reconhece algumas letras, se ele já tá sabendo cores. $\mathrm{Na}$ sala regular eu já vou ver nas nossas provinhas qual é o conteúdo que ela tá sentindo dificuldade se é na Matemática, quais os números e a gente sempre procura fazer com eles pra ver realmente onde é que eles estão sentindo dificuldade nesse conteúdo. (P1)

O que influencia o meu processo avaliativo para que seja da forma citada está relacionada à condição de cada um, ou seja, utilizo o critério e o instrumento de acordo ou de forma que o aluno possa dar resposta a este instrumento. (P2)
\end{abstract}

As falas de P1 e P2 se aproximam ainda que uma análise mais minuciosa denote que os objetivos são bem distintos. Enquanto uma busca avaliar com foco nos conteúdos formais e estruturais a outra professora se detém em acompanhar o desenvolvimento global do estudante, mas sem deixar de ter como ponto primordial o conhecimento e a compreensão das limitações de cada estudante, o que contribui de maneira significativa, pois se fazem possíveis intervenções mais eficazes.

Não se pode menosprezar que a prova realizada tem importante papel, não classificatório, mas serve para P1 mensurar o quanto o aluno está se apropriando dos conteúdos ministrados em sala e daí detectar as principais dificuldades do aluno. É a partir desta avaliação formativa e não somativa que o professor poderá traçar planos, desenvolver métodos e metodologias que orientem os processos interventivos e não 
apenas estes, mas que respeitem o direito de avaliações adaptadas e adequadas às condições de cada estudante.

Faz-se mister não fazer da avaliação um processo excludente, antes deve aproximar as realidades da sala regular e da sala do Atendimento Educacional Especial. A avaliação na fala de Luckesi (2011) deve ser um processo acolhedor e não distanciador deve valorizar os conhecimentos já existentes e deve ser aplicada utilizando instrumentos adequados à realidade e a deficiência de cada aluno

O instrumento ou a aplicação deste instrumento deverá ser diferente com vistas à adaptar o processo avaliativo frente à deficiência/defasagem do aluno, devem oferecer informações sobre a aprendizagem atual de cada aluno, a forma como enfrentam os desafios em diversas situações de aprendizagem, suas estratégias e respostas frente às atividades. Cada instrumento avaliativo deve propiciar uma resposta devida para que se possa medir/quantificar a aprendizagem do aluno (FERNANDES E VIANA, 2010).

Ainda sobre os processos avaliativos, foi questionado apenas à professora da sala regular (P1) se a avaliação da aprendizagem do aluno com deficiência é a mesma utilizada com os alunos que não tem deficiência. A mesma foi bastante incisiva na resposta.

Sim a avaliação escrita é a mesma, mas a forma de avaliação não. Porque a das outras crianças a gente entrega a provinha, deixa que leiam, que respondem livremente, lê com ele e as crianças que tem deficiência a gente vai dando conhecimentos prévios pra eles e, às vezes, o aluno que não é especial a gente avalia da forma que a gente sabe que ele entende, da forma que a gente sabe que ele tinha capacidade de responder aquela pergunta e a criança especial a gente avalia aproveitando o máximo do que ela fez na avaliação, tendo em vista que ela tem um atraso, a gente já aproveita tudo que pode na avaliação dela. (P1)

Há certa continuidade do questionamento realizado quanto aos critérios e instrumentos utilizados para a avaliação em que ela afirma a diferença apenas na aplicação do instrumento avaliativo e não no instrumento. Vê-se que a professora também monitora de uma forma diferenciada o desempenho do aluno, se identifica um cuidado para que o desenvolvimento da criança seja global, buscando aproximar o objeto do sujeito e vice-versa, considerando conhecimentos prévios, conhecimentos atuais e possíveis conhecimentos futuros (BRASIL, 2008).

Perrenoud (1999) ratifica ao tratar da avaliação numa perspectiva formativa, como sendo aquela que ajuda o aluno a aprender e a se desenvolver. Para tanto, trata 
também de algumas adequações como: demanda de maior tempo para aprendizagem e avaliação, maior concretude nas atividades, ressalta a responsabilidade do professor que assume uma proposta de avaliação formativa, no sentido de se conceber como alguém capaz de fazer todos os alunos aprenderem respeitando sua individualidade.

A pergunta comum às duas professoras $\mathrm{P} 1$ e $\mathrm{P} 2$ acerca de como as mesmas veem o aluno com deficiência com relação à aprendizagem e avaliação na perspectiva da escola inclusiva revela, por P1, a importância do acolhimento, aceitação, interação como forma de atingir melhor o desenvolvimento cognitivo desse aluno.

Bom eu acredito que o aluno estando incluso na escola, ele tem sim a capacidade de evoluir, inclusive já vi situações em que as crianças chegam na escola com alguns conhecimentos e saem com outros conhecimentos extras não só cognitivos mas também sociais. Outra coisa também que a gente pode ressaltar é... ele está sempre contato com os outros alunos na mesma sala com outras crianças, porque elas já entendem o que acontece com aquela criança e aí dão suporte e ajudam no crescimento delas. Tem crianças que chegam à escola que ficam quietos e depois de um tempo você já vê ele normal com a outra criança, brincando com as outras crianças, uma sente dificuldade em ficar na sala querem descer e aí esse costume de está na escola eles vão aprendendo que existem algumas regras que a gente precisa obedecer no nosso dia a dia, na nossa vida social, no nosso dia a dia e aí começam a compreender que eles precisam está na sala de aula. E isso vai ajudando pra eles é... Quando eles estiverem maiores, mais preparados pro mundo e em relação ao cognitivo por mais que não acompanhem o conteúdo, eles vão ter um conhecimento prévio pra mais na frente quando for abordar no AEE, poderem fazer essa ligação entre os conhecimentos. (P1)

Por sua vez P2 relatou acerca do que a escola já proporcionou aos alunos com deficiência do ponto de vista das perspectivas de aprendizagem denotando, portanto, o caráter inclusivo, neste aspecto, da escola. Porém a professora não responde com devida clareza a sua visão entre perspectivas de aprendizagem e avaliação da aprendizagem deste aluno. A professora exemplifica, mas sem uma conceituação anterior consistente. Assim responde:

Pelo trabalho que a gente realiza nós já temos conseguido algumas coisas favoráveis porque a gente tem esse momento exclusivo na sala, aonde eles vêm e eu procuro desenvolver eles dentro das capacidades de cada um. Nós já tivemos alunos com Paralisia Cerebral e que saíram daqui para o (escola) em condição de fazer um quinto ano, crianças que não falam que não se movimentam então assim nós temos conseguido, desta forma, que a gente trabalha. (P2) 
Percebe-se o compromisso das professoras diante do aluno, manifestado nos cuidados, na atenção e principalmente na importância do aluno no espaço escolar e suas relações com os demais estudantes, rememoram o que Vygotsky aponta sobre a interação entre sujeito e objeto, característica da Teoria Sócio Interacionista, de onde o mesmo compreende o processo de ensino-aprendizagem composto pelo sujeito que aprende, o sujeito que ensina e a relação entre os dois. Para aquele autor há evolução quando a criança, com auxílio de um adulto consegue desenvolver os problemas apresentados (SANTOS, 2014).

A responsabilidade da escola não é oferecer ensino diferenciado para alunos selecionados, mas adequar as práticas pedagógicas à necessidade que cada estudante necessita. Neste interim é válido destacar alguns entraves ao cuidado com esse estudante como a formação docente e as dificuldades de recursos didático-pedagógicos podem implicar no desenvolvimento do fazer pedagógico.

O fato de ser uma criança com deficiência e/ou com qualquer outra situação de superdotação, altas habilidades ou transtornos de desenvolvimento não implica necessariamente que a criança seja limitada em sua aprendizagem e se esta postura for tomada pelo profissional professor assim como os demais profissionais da instituição escolar se presencia a exclusão dentro da modalidade da educação que deveria incluir, além do preconceito de forma desvelada.

P2 foi questionada se, de acordo com sua prática, que torna possível uma observação mais atenta da sala regular, sugeriria outros critérios e instrumentos de avaliação da aprendizagem do aluno com deficiência que poderiam ser adotadas na sala regular e que garantiriam uma melhor inclusão escolar.

Geralmente nas salas que tem aluno com deficiência há uma pessoa responsável. Então eu vejo que já é uma coisa estudada pela secretaria da escola, pela coordenadora e eu acredito que está dentro das possibilidades da escola. (P2).

A resposta da professora não identifica uma sugestão voltada para o instrumento ou critério avaliativo que a pergunta contemplou. Ressaltou apenas a figura do cuidador e a intensa preocupação da gestão em adequar a escola às necessidades dos alunos. A mesma exime-se da responsabilidade de criar e desenvolver novos métodos e novas práticas para alocar em outros atores do sistema educacional. 
Segundo as Estratégias e Orientações Para a Educação de Crianças com Necessidades Educacionais Especiais a escola deve adotar formas flexíveis de avaliação quanto ao desenvolvimento e o processo de aprendizagem dos estudantes (BRASIL, 2000), todavia o estudo de Oliveira e Araújo (2017) encontra certo engessamento no discurso docente, deixando claro que o discurso inclusivo aponta apenas para o fato do aluno estar na sala, sem que sejam desenvolvidas metodologias específicas para cada situação.

A relação estabelecida entre a inclusão escolar e a efetiva aprendizagem do aluno com deficiência não teve clara relação estabelecida pelas professoras. P1 expõe sua preocupação com o aprendizado dos alunos com deficiência enquanto P2 sugere uma visão de inclusão voltada para a socialização e aceitação da deficiência como promotora de aprendizagens.

Como eu disse aqui na escola a gente tem duas formas de avaliação, que é a forma da sala de aula e a forma que é feito no AEE. Isso é muito rico porque a gente tem duas formas de ver como ele está se saindo dentro de sala, que no caso é comparar o conhecimento que ele tem com a meta que a gente tem a atingir e avaliação que é feita no atendimento a gente compara onde ele está com as metas que ele mesmo tem pra poder superar e aí a gente tenta... Eu e a professora do AEE ver onde ele está em relação à sala, aos conhecimentos dela mesmo, e eu acho que é isso que faz uma educação inclusiva é você sempre está trabalhando com o aluno, até onde ele pode chegar e trabalhar isso junto com a outra professora. (P1)

A Educação Inclusiva é percebida de forma superficial enquanto a avaliação toma caráter de ser necessária à percepção e diagnóstico do processo evolutivo do aluno, não como processo que classifica como Luckesi (2001) corrobora ao tratar do acolhimento dos alunos com suas carências apontando a necessidade de novas práticas e completudes pedagógicas e a partir daí propor ações coerentes (intencionalidade pedagógica) com as perspectivas do aluno.

Hoffmann (2009) destaca o fato de se levar em consideração as condições próprias de cada aluno a partir do favorecimento de uma oportunidade máxima de aprendizagem. A fala da professora também remete ao que está preconizado na Política Nacional de Educação Especial na perspectiva da Educação Inclusiva elaborada pelo MEC ao tratar da avaliação como um processo que deve considerar o desenvolvimento atual do aluno e suas possibilidades de aprendizagem futura (BRASIL, 2008). Ademais é importante desenvolver no estudante a autoestima. 
Com certeza o aluno que tem problema, que ele interage com outros alunos, se vê uma pessoa igual aos outros, não se vê uma pessoa excluída, ele tem uma condição melhor de aprender, gera nele um auto-confiança, onde ele tem uma condição melhor de aprender. (P2)

A mesma sugere uma visão de inclusão voltada para a socialização e aceitação da deficiência. Segundo a mesma, isto favorece a autoconfiança do aluno e sua consequente aprendizagem. No entanto, não sugere claramente a relação entre avaliação da aprendizagem e inclusão escolar.

\section{Considerações finais}

A leitura e reflexão do mesmo por outros profissionais ligados à escola, mais especificamente professores em geral e à própria gestão escolar pode trazer um novo olhar acerca do assunto abordado, do ponto de vista, de sensibilização e abrangência dos conceitos expostos. Os termos Avaliação e Inclusão, cada um com sua complexidade, dá ao trabalho um posicionamento de não esgotamento de si mesmo. Compreendê-los na sua totalidade e buscar uma avaliação do aluno com deficiência requer conhecimento e comprometimento diários de toda a escola. Ficou evidente, no campo pesquisado, empenho e responsabilidades iguais percebidas entre as duas professoras, diferentemente do que se inferiu introdutoriamente.

Do cenário observado e investigado conclui-se a existência de algumas lacunas. Inicialmente, do ponto de vista formativo conceitual, relacionado à concepção do que seja avaliação da aprendizagem do aluno. De uma maneira geral, percebe-se um posicionamento mais bem apropriado, até mesmo em relação ao que é desenvolvido no Atendimento Educacional Especializado da escola na fala da professora da sala regular. Essa consistência no discurso da mesma favorece ou sugere que há desenvolvimento de práticas avaliativas inclusivas e, consequentemente do aprendizado dos alunos. Isso, porém, já não é detectado com devida clareza e consistência no discurso da professora do AEE, principalmente nos aspectos conceituais do que seria avaliação da aprendizagem.

Quanto aos processos avaliativos voltados para o aluno com deficiência percebese que as professoras buscam no seu dia a dia adaptar, reajustar a partir de um modelo comum, no caso da professora da sala regular, o processo avaliativo, havendo mudanças apenas na forma de aplicação do instrumento avaliativo, que leva em consideração a deficiência do aluno. Ainda sobre a relevância da relação entre avaliação da 
aprendizagem e inclusão escolar, embora não tenha sido estabelecida uma relação clara pelas professoras entre os mesmos, vê-se nos discursos das docentes uma importante preocupação e um notável esforço no sentido de buscar metodologias, de detectar diversas maneiras as aprendizagens que o aluno com deficiência realiza do ponto de vista comportamental, social e também cognitivo.

Isso indica uma postura da escola de busca por uma prática inclusiva voltada para esses alunos ao garantir que diversas aprendizagens sejam realizadas e devidamente avaliadas a partir da perspectiva de cada um. Tendo em vista o apontado, fica inferido da escola uma concepção formativa de avaliação também direcionada aos alunos com deficiência.

\section{REFERÊNCIAS}

BRASIL. Constituição da República Federativa do Brasil. Brasília: Imprensa Oficial, 1988.

BRASIL. Lei de Diretrizes e Bases da Educação Nacional. São Paulo: Brasília, 1996.

CARVALHO. Vírginia Donizete de.; BORGES. Lívia de Oliveira.; RÊGO. Denise Pereira do. Interacionismo simbólico: origens, pressupostos e contribuições aos estudos em psicologia social. Psicol. cienc. prof. [online], v. 30, n. 1, p.146-161, 2010. ISSN 1414-9893.

ESTEBAN. Maria Paz Sandín. Pesquisa Qualitativa em educação: fundamentos e tradições. Porto Alegre: AMGH, 2010.

SANTOS FILHO, José Camilo dos. Pesquisa quantitativa versus pesquisa qualitativa. O desafio paradigmático. In: SANTOS FILHO, José Camilo dos.; GAMBOA, Silvio Sanchez (Orgs.). Pesquisa educacional: quantidade - qualidade. 2 ed. São Paulo: Cortez, 1997.

HOFFMANN. Jussara. Avaliar para promover: as setas do caminho. Porto Alegre: Mediação, 2009.

HOFFMANN. Jussara. Pontos e contrapontos: do pensar ao agir em avaliação. Porto Alegre: Mediação, 2005.

HOFFMANN. Jussara. Avaliação: mito e desafio - uma perspectiva construtivista. Porto alegre: Mediação, 2008.

LUCKESI. Cipriano Carlos. Avaliação da aprendizagem escolar. São Paulo: Cortez, 2010 . 
LUCKESI. Cipriano Carlos. Avaliação da aprendizagem: estudos e proposições. 6. ed. São Paulo: Cortez, 1997.

MITTLER. Peter. Educação Inclusiva: contextos sociais. Tradução Windyz Brazão Ferreira. Porto Alegre: Artmed. 2003.

ORGANIZAÇÃO DAS NAÇÕES UNIDAS. Convenção sobre os Direitos das Pessoas com Deficiência, 2006.

PERRENOUD. Philippe. Avaliação: da excelência à regulação das aprendizagens entre duas lógicas. Tradução de Patrícia Chittoni Ramos. Porto Alegre: Artmed, 1999.

\section{Política Nacional de Educação Especial na Perspectiva da Educação Inclusiva.}

Ministério da Educação (Jan. 2008). Disponível em <http:

//portal.mec.gov.br/pdf/politicaeducespecial.pdf>. Acesso em: 05 maio 2013.

PONTES. Patrícia Albino Galvão. Criança e adolescente com deficiência: impossibilidade de opção pela sua educação exclusivamente no atendimento educacional especializado. Inclusão: revista da Educação Especial, Brasília, v. 4, n. 1, p.41-48, jan./jun. 2008.

ROMÃO. José Eustáquio. Avaliação dialógica: desafios e perspectivas. 3.ed. São Paulo. Cortez.

SANTOS. Rita de Cássia Andrade Neiva. Fui ficando e engravidei: trajetória da primeira gestação na adolescência (Tese de Doutorado). Universidade de Fortaleza. Programa de Pós-Graduação em Saúde Coletiva. Fortaleza - 2014.

VIANA, T. U.; CIASCA, L. M. F.; SOBRAL, A.E. Múltiplas dimensões em avaliação educacional. Fortaleza: Iprece, 2010.

VIANNA. H. M. Avaliação educacional: teoria, planejamento, modelos. São Paulo: IBRASA, 2000.

\section{Como referenciar este artigo}

NASCIMENTO, Romária de Menezes.; SOARES, Ana Cristina Silva.; SILVA, Rejane Maria Gomes da.; PINTO, Francisco Ricardo Miranda. Verificação da aprendizagem do aluno com deficiência na perspectiva da inclusão escolar. Revista on line de Política e Gestão Educacional, Araraquara, v. 21, n. esp.2, p. 1316-1334, nov. 2017. Disponível em: <http://dx.doi.org/10.22633/rpge.v21.n.esp2.2017.10187>. ISSN: 1519-9029.

Submetido em: 30/09/2017

Aprovado em: 30/10/2017 